\title{
Turner's Syndrome in Adulthood and Cytogenetics
}

\author{
Hossain $\mathbf{F}^{1}$, Nahar KN', Mahmoud $\mathbf{S}^{1}$, Islam FA², Begum $\mathbf{N}^{1}$, Akhter $\mathbf{P}^{1}$ \\ ${ }^{1}$ Department of Obstetrics and Gynaecology, Bangabandhu Sheikh Mujib Medical University, ${ }^{2}$ Department of Neurosur- \\ gery, National Institute of Neurosciences, Dhaka, Bangladesh
}

Received: February 8, 2013; Accepted: August 12, 2014

\begin{abstract}
Aims: Turner's syndrome is a chronic disease of chromosomal aberration. The purpose of the study was to find out the accurate identification of cell line, which is critical for cytogenetic studies, genetic counseling, phenotypic studies carried out with few reconstructive procedures to plan future sexual and reproductive life.

Methods: This study design was a prospective hospital based clinical study. In this study, ninety six patients were studied with secondary sex characters with relevant ultrasonogram findings and hormonal assay who underwent karyotyping in Bangabandhu Sheikh Mujib Medical University, Dhaka for a study period of ten years from October 1997 to October 2007.

Results: Among 96 patients, $62.5 \%$ of the patients were from $15-18$ years. Four girls who were less than 15 years came with Turner's and testicular stigmata. Twenty women aged more than 26 years presented with coital problems. Around $72.9 \%$ had no secondary sexual character, $20.83 \%$ had normal female type of secondary sex character, and $6.25 \%$ had virilizing type of secondary sexual character. Karyotyping of the cases revealed $72.9 \%(n=70)$ had $45 X O$ pattern, which belong to the Turner's stigmata and correlated well with the hormone profile. Whereas, $20.83 \%(n=20)$ had $46 X X$ pattern and $6.25 \%(n=6)$ had $46 \mathrm{XY}$ pattern with testicular feminization syndrome with inguinal testis.
\end{abstract}

Conclusions: About $60 \%$ of cases were in the 15-18 years age group. Most of the patients presented with no secondary sexual characteristics. $45 \mathrm{XO}$ chromosomal pattern was the most common presenting in $72.9 \%$ cases.

Keywords: cytogenetics; karyotype; phenotype; Turner's syndrome.

\section{INTRODUCTION}

Turner's syndrome is the most common chromosomal abnormality in females affecting 1:2,500 live female births. It is a result of absence of an $\mathrm{X}$ chromosome or the presence of a structurally abnormal $\mathrm{X}$ chromosome. Several variation of this syndrome occurs as a result of chromosomal abnormalities such as mosaics (XO/XX is the most common) structural abnormalities of the $\mathrm{X}$ chromosome and a gene defect (pure gonadal dysgenesis). ${ }^{1}$

Turner's syndrome cases are susceptible to osteoporosis, hypothyroidism, dyslipidemia, renal

\section{CORRESPONDENCE}

Dr Fawzia Hossain

Department of Obstetrics and Gynaecology, Bangabandhu Sheikh Mujib Medical University, Dhaka, Bangladesh.

Email: islamaraferdous@yahoo.com

Phone: +8801715300515 and gastrointestinal disease. They are often diagnosed prior to puberty for the phenotypic features. Autoimmune diseases and thyroid diseases are very common. ${ }^{2}$ They have a reduced life expectancy and recent evidence suggests they have an increased risk of aortic dissection and ischemic heart disease. ${ }^{3}$ Our objective of the study was to determine the cases and type of chromosomal aberration in primary amenorrhoea to formulate the future plan of sexual and reproductive life.

\section{METHODS}

The study design was a prospective type of hospital based clinical study. Ninety-six women presenting with primary amenorrhoea with Turner's stigmata were studied from October 1997 to October 2007 at the Gynaecology outpatient department of Bangabandhu Sheikh Mujib Medical University, 
Dhaka, Bangladesh. Prior permission was taken from the hospital authority. All the relevant data were collected from the patients after taking informed written consent. In case of younger patients, consent was taken from the parents or guardian. Relevant history, examination findings and investigations were recorded. Physical findings including developmental parameters, normality of genitalia and confirmation of presence or absence of vagina, uterus and ovaries were done by transvaginal ultrasonography. Gonadotrophins (FSH and LH) estimation and sex steroid hormone profile was done. Barr body or sex chromatin visualization was the most frequently used technique to identify the inactivated $\mathrm{X}$ chromosome in normal 46XX female. With all these possibilities in mind, cytogenetic study of primary amenorrhoea was done to find out the pattern of chromosomal abnormality in a selected group of patients. Exclusion criteria included patients who were negative to other causes of primary amenorrhoea, particularly those $45 \mathrm{XO}$ cases without Turner's stigmata, mosaics and pseudohermaphrodites that did not have menses. In 45XO and 45XY females they were negative. The test was done from buccal smear or peripheral blood. Sex chromatin or Barr body appeared as triangular dark body attached to nuclear membrane. Venous blood was drawn for karyotyping and leukocyte culture method was followed with phytohaemagglutinin as mitogenic agent. Colchicine was added to arrest cell division at metaphase. Slides were fixed, prepared and stained by Giemsa technique. The results of karyotyping were correlated with clinical findings.

\section{RESULTS}

Out of 96 respondents majority of the patients, 60 $(62.5 \%)$ were from $15-18$ years of age with mean age of 16.2 years of age. Again, $20(20.8 \%)$ patients were from 19-26 years of age, 12 (12.5\%) patients were above 26 years of age and only 4 (4.2\%) patients were below 15 years of age. Among the 96 participants 24 (25\%) were married and 72 (75\%) were not married. Majority $(81 \%)$ of the patients were poor and $19 \%$ come from lower middle socioeconomic status.

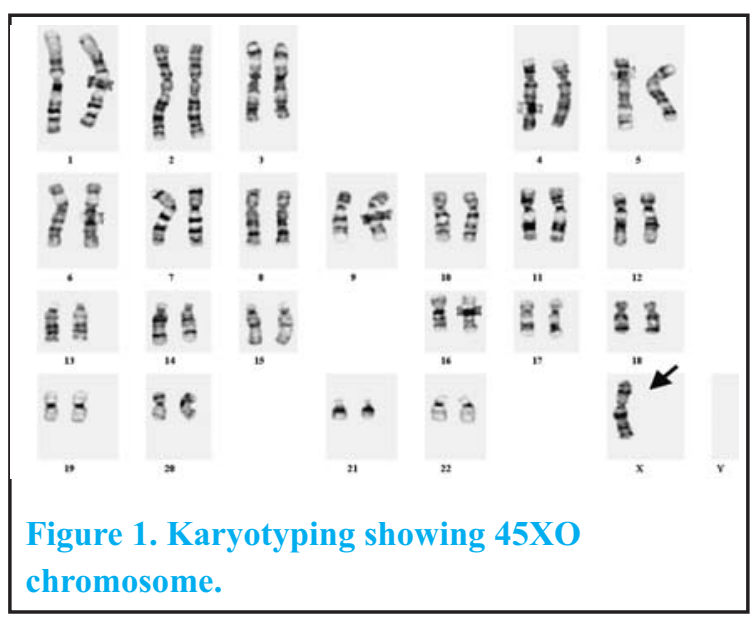

Among the 96 cases studied for karyotyping, 72.9\% $(\mathrm{n}=70)$ cases had the stigmata for abnormal karyotype (Figure 1), 20.83\% ( $\mathrm{n}=20)$ cases had normal female sex characteristics and $6.25 \%(n=6)$ had the virilizing characteristics (Table 1).

\begin{tabular}{|c|c|c|}
\hline $\begin{array}{l}\text { Karyotyping of } \\
\text { the patent }\end{array}$ & $\begin{array}{l}\text { Secondary } \\
\text { sex } \\
\text { character }\end{array}$ & $\begin{array}{l}\text { Percentage } \\
(\%)\end{array}$ \\
\hline Group A (45XO) & $\begin{array}{l}\text { No } \\
\text { secondary } \\
\text { sex } \\
\text { character, } \\
\text { short stature } \\
\text { and webbing } \\
\text { of neck }\end{array}$ & 6 \\
\hline Group B (46XX) & $\begin{array}{l}\text { Normal } \\
\text { secondary } \\
\text { sex character }\end{array}$ & 21 \\
\hline Group C (46XY) & $\begin{array}{l}\text { Virilizing } \\
\text { type, tall } \\
\text { female with } \\
\text { secondary } \\
\text { sex and } \\
\text { inguinal } \\
\text { testis }\end{array}$ & 73 \\
\hline
\end{tabular}

Breast was well developed among 20 (20.83) \% cases, Rokitansky syndrome was present among 28 $(29.16 \%)$ cases, infantile uterus was present in 20 $(20.83 \%)$ cases and the uterus was absent in $12(12.5$ $\%$ ) cases. Normal uterus was present in $6(6.25 \%)$ cases (Table 2). 
Table 2. Distribution of secondary characteristics among respondents $(n=96)$.

\begin{tabular}{lr}
\hline Secondary sex organs & \multicolumn{1}{c}{ Total } \\
Breast well developed & 20 \\
& $(20.83 \%)$ \\
Breast not well developed & 60 \\
Absent uterus or nodule and & $(62.50 \%)$ \\
absent vagina (Rokitansky syndrome) & $(29.16 \%)$ \\
Infantile uterus and normal vagina & 20 \\
& $(20.83 \%)$ \\
Absent uterus and blind vagina & 12 \\
& $(12.50 \%)$ \\
Cryptomenorrhoea & 10 \\
Normal uterus, vagina with pinhole & $(10.40 \%)$ \\
hymen & $(4.16 \%)$ \\
Normal uterus and vagina & 6 \\
\end{tabular}

For the correction of coital and menstrual problem, vaginal reconstructive surgery was done in 20 cases and another 2 patients had undergone total abdominal hysterectomy (Table 3).

\begin{tabular}{|lc|}
\hline \multicolumn{2}{|l|}{$\begin{array}{l}\text { Table 3. Distribution of operative treatment among } \\
\text { the respondents }(\mathrm{n}=22) .\end{array}$} \\
\hline Operative treatment & Total \\
Colon grafting & $8(8.30 \%)$ \\
Amnion grafting & $8(8.30 \%)$ \\
Hymenectomy & $4(4.16 \%)$ \\
Hysterectomy & $2(2.08 \%)$ \\
\hline
\end{tabular}

\section{DISCUSSION}

Among the 96 cases studied, around $72.9 \%$ cases had the stigmata for abnormal karyotype (45XO), no secondary sex character and had short stature and webbing of neck. A 45 X karyotype is observed in $1 \%$ to $2 \%$ of conceptuses, $10 \%$ of miscarriages and $1 \%$ of stillbirths. Greater than $99 \%$ of $45 \mathrm{X}$ conceptuses result in spontaneous loss, usually before 28 weeks. The reason why $1 \%$ survive to term with relatively minor somatic abnormalities is not known, although it has been hypothesized that this is due to undetected mosaicism for a cell line with all or part of a second sex chromosome. ${ }^{4,5}$ Cytogenetic abnormality was identified in $3 / 4^{\text {th }}$ of the cases of primary amenorrhoea. Our objective of the study was also to plan the future sexual and reproductive life. There is a possibility that a $45 \mathrm{XO}$ patient may have a mosaic line in the gonads. This would not be detected on a karyotype in a leukocyte culture. A Y containing gonad is at risk for the development of a gonadoblastoma or dysgerminoma. ${ }^{6}$ An annual pelvic examination should be carried out to survey for an adnexal mass. If a $45 \mathrm{XO}$ patient develops breasts or sexual hair without hormone replacement therapy, a gonadal tumor should be excluded as a diagnosis. Females with short stature and deletion of the distal region of Xp including the SHOX gene are generally not diagnosed with Turner syndrome. Likewise, individuals with deletions of Xq24 with primary or secondary amenorrhea without short stature are typically diagnosed with premature ovarian failure. ${ }^{7}$

Turner Syndrome is sporadic. A majority of cases ascertained prenatally have a 45XO karyotype. Paternal non disjunction accounts for $70 \%$ of live born cases with a $45 \mathrm{XO}$ chromosome. ${ }^{89}$ Monosomy $\mathrm{X}$ is frequently identified by prenatal diagnostic procedures. Ultrasound findings can include nuchal translucency, cystic hygroma, coarctation of the aorta and/or other left-sided heart defects, brachycephaly, renal anomalies, polyhydramnios, oligohydramnios, and growth retardation. Abnormal prenatal serum marker screening results with elevated levels of human chorionic gonadotropin and inhibin and slightly decreased levels of alpha fetoprotein and unconjugated estriol are associated with an increased likelihood of a Turner syndrome diagnosis. ${ }^{10,11}$ If the patient reveals an apparently nonmosaic 45,X karyotype and has clitoromegaly or other masculinizing features, it is very likely that there is mosaicism for a Y chromosome containing cell line. FISH with probes for the $\mathrm{X}$ and $\mathrm{Y}$ centromeres should be performed on a minimum of 200 cells to detect low-level Y chromosome mosaicism. Given the high suspicion for Y chromosome material, study of a second cell type may be warranted. Consultation with the referring physician is recommended. Referral for genetic counseling and evaluation by a clinical geneticist and/or other appropriate health care provider. ${ }^{7}$ When a karyotype consistent with Turner 
syndrome is found prenatally, postnatal chromosome analysis is recommended to document the child's karyotype. $^{12}$

Among the 96 cases, $70 \%$ were in the age range of 15 to 18 years. Four girls aged less than 15 years came with Turner's and Testicular stigmata. Hormonal replacement therapy should be instituted. At approximately age 12 to 13 , eostrogen therapy is given in a dose of $0.3 \mathrm{mg}$ conjugated eostrogen during the first three weeks of each month followed by $5 \mathrm{mg}$ of medroxy progesterone acetate from the $12^{\text {th }}$ to the $21^{\text {st }}$ day. ${ }^{13}$ This dosage will be sufficient to cause a growth spurt and development of secondary sexual characteristics. Following puberty development, the dose of eostrogen replacement is gradually increased to $0.625 \mathrm{mg}$ and then to $1.25 \mathrm{mg}$. A recent study reported that oral ethinyl oestradiol (E2) treatment regimen for Turner's syndrome girls have given rise to satisfactory puberty induction and maintenance, but failed to induce a fully mature uterus in half the cohort. In view of the high risk of miscarriages in TS in both spontaneous and assisted pregnancies, the effect of more physiological methods of E2 replacement on uterine development should be investigated. ${ }^{14}$ In normal ovulating women, the majority of bone mass is acquired by the end of the second decade. ${ }^{15}$ Most of the increase in bone size and density occurs early in puberty. In light of the high incidence of renal, cardiac and auditory abnormality in-patients with Turner's syndrome, the initial workup should include a renal ultrasound, echocardiography and audiometry. The thyroid function, lipid profiles and serum glucose should be evaluated annually. ${ }^{6}$

In current study, twenty-four women were married. Twenty women around 26 years age had coital problems for one year and four of them had no sexual dysfunction and had a conjugal life for 5 years. A neovagina may be created in either a surgical or non-surgical fashion. A non-surgical approach, the Frank technique, involves the use of intermittent pressure with vaginal dilators to create a neovagina. The McIndoe procedure uses a split thickness skin graft around a solid rubber mould for the creation of an artificial vagina. ${ }^{16}$ This technique has been modified and gynaecologists with use of amnion grafts, and also laparoscopic approaches to use bilateral vulvoperineal fasciocutaneous flaps. ${ }^{17}$ In a cross-sectional multidisciplinary study of 53 women, more social isolation was reported than the normative group. They suffered from more emotional distress and experienced more difficulties in the area of social and partner relationships. ${ }^{18}$ Psychological well-being and self-rated health were poor among the group of Turner we studied.

\section{CONCLUSIONS}

Among the patients with Turner syndrome, primary amenorrhea was quite high $(2.33 \%)$. These patients suffered from more emotional distress and experienced more difficulties in the area of social and partner relationships. About $60 \%$ of cases were in the 15-18 years age group. Most of the patients presented with no secondary sexual characteristics. $45 \mathrm{XO}$ chromosomal pattern was the most common feature.

\section{ACKNOWLEDGEMENT}

The authors are deeply thankful to the patients who presented with primary amenorrhoea with Turner's stigmata. Without their kind cooperation the study would have been futile.

\section{DISCLOSURE}

The authors report no conflicts of interest in this work.

No violation of human rights and safety.

Funding: Nil 


\section{REFERENCES}

1. Speroff L, Glass RH, Kase NG, editors. Clinical gynecologic endocrinology and infertility. 5th edn. Baltimore: Williams and Wilkins; 1994. p. 401-56.

2. Mitsibounas DN, KosmaidouZ. Hyperlipidaemia and presence of thyroid autoantibodies in girls with Turner's syndrome. J Pediatr Adolesc Gynecol. 1997; 10:133-9.

3. Elsheikh M, Dunger DB, Conway GS. Turner's syndrome in adulthood. Endocr Rev. 2002 -23(1):120-40.

4. Hook EB, Warburton D. The distribution of chromosomal genotypes associated with Turner's syndrome: live birth prevalence rates and evidence for diminished fetal mortality and severity in genotypes associated with structural $\mathrm{X}$ abnormalities or mosaicism. Hum Genet. 1983;64:24 -27.

5. Held KR, Kerber S, Kaminsky E, Singh S, Goetz P, Seemanova E, et al..Mosaicism in 45,X Turner syndrome: does survival in early pregnancy depend on the presence of two sex chromosomes ? Hum Genet. 1992;88:288 -94

6. Speroff L, Fritz MA. Amenorrhea. In: Speroff L, Glass RH, Kase NG, editors. Clinical gynecologic endocrinology and infertility. 7th ed. Philadelphia: Lippincott Williams \& Wilkins; 2005;401-64.

7. Bondy CA. Care of girls and women with Turner syndrome: a guideline of the Turner Syndrome Study Group. J Clin Endocrinol Metab. 2007; 92: 10-25.

8. Mathur A, Stekol L, Schatz D, Maclaren NK, Scott ML, Lippe $\mathrm{B}$. The parental origin of the single $\mathrm{X}$ chromosome in Turner syndrome: lack of correlation with parental age or clinical phenotype. Am J Hum Genet. 1991;48:682-6.

9. Skuse DH, James RS, Bishop DVM, Coppin B, Dalton P, Aamodt-Leeper, G Et al. Evidence from Turner's syndrome of an imprinted X-linked locus affecting cognitive function. Nature. 1997;387:705-8.
10. Wenstrom KD, Chu DC, Owen J, Boots L. Maternal serumfetoprotein and dimeric inhibin A Detect aneuploidies other than Down syndrome. Am J Obstet Gynecol. 1998;17(9):966 -70 .

11. Ruiz C, Lamm F, Hart PS. Turner syndrome and multiplemarker screening. Clin Chem. 1999;45:2259 -61.

12. Gravholt CH, Juul S, Naeraa RW, Hansen J. Prenatal and postnatal prevalence of Turner's syndrome: a registry study. BMJ. 1996;321:16 -21.

13. Lev-ran A. Androgens, estrogens, and the ultimate height in XO gonadal dysgenesis. Am J Dis Child. 1977;131(6):648-9.

14. Paterson WF, Hollman AS, Donaldson MD. Poor uterine development in Turner syndrome with oral oestrogen therapy. Clin Endocrinol (Oxf). 2002;56(3):359-65.

15. Gilsanz V, Gibbons DT, Roe TF. Vertebral bone density in children: effect of puberty. Radiology. 1988;16(6):847-50

16. McIndoe $\mathrm{AH}$, Banister JB. An operation for the cure of congenital absence of the vagina. J Obstet Gynaecol $\mathrm{Br}$ Commonw. 1938;45:490-4

17. Giraldo F, Solano A, Mora MJ, Rus JA. The Malaga flap for vaginoplasty in the Mayer- Rokitansky-Kuster-Hauser syndrome. Plast Reconstr Surg. 1996;98:305-12.

18. Boman UW, Bryman I, Halling K, Mollar A. Women with Turner syndrome: psychological well-being, selfrated health and social life. J Psychosom Obstet Gynaecol. 2001;22(2):113-22. 